\title{
Correction to: The proliferation marker pKi- 67 becomes masked to MIB-1 staining after expression of its tandem repeats
}

\author{
Mirko H. H. Schmidt ${ }^{2} \cdot$ Rainer Broll $^{1} \cdot$ Hans-Peter Bruch ${ }^{1} \cdot$ Michael Duchrow $^{1}$
}

Published online: 20 November 2018

c) Springer-Verlag GmbH Germany, part of Springer Nature 2018

\section{Correction to: Histochem Cell Biol (2002) 118:415-422 https://doi.org/10.1007/s00418-002-0464-5}

In the PubMed citation records, the author's name shows as "Schmidt MH" and the author wants to have it as "Schmidt MHH" as mentioned in the original paper and it should be as follows:

The proliferation marker $p K i-67$ becomes masked to MIB-1 staining after expression of its tandem repeats, Schmidt MHH, Broll R, Bruch HP, Duchrow M, Histochemistry and cell biology, 2002, 118(5): 415-422.

The original article can be found online at https://doi.org/10.1007/ s00418-002-0464-5.

Michael Duchrow

duchrow@medinf.mu-luebeck.de

1 Surgical Research Laboratory, Department of Surgery, Medical University of Lübeck, Ratzeburger Allee 160, 23538 Lübeck, Germany

2 Henry Ford Hospital, Hermelin Brain Tumor Center, Department of Neurosurgery, 2799 W. Grand Blvd., Detroit, MI 48202, USA 